\title{
A FENOMENOLOGIA OLHADA POR MIRANDA BARBOSA E EDUARDO ABRANCHES DE SOVERAL
}

\author{
Pedro M. S. Alves \\ Universidade de Lisboa
}

Eduardo Abranches de Soveral pertence à geração de pensadores que traz a fenomenologia para o panorama filosófico português, especificamente para a Universidade.

De facto, embora os cruzamentos sejam constantes, pode distinguir-se entre, de um lado, a filosofia em contexto académico, tal como se pratica no trabalho universitário pela discussão de problemas específicos e pelo conhecimento histórico das doutrinas, e, do outro lado, a filosofia como viva produção intelectual dirigida ao mundo e imediatamente presente no espaço público. Trata-se, em suma, da distinção entre a filosofia que se ensina e a filosofia que se faz. A primeira nem sempre coincide com a segunda, não só por um efeito natural de retardamento (a filosofia tal qual se produz não é ainda a filosofia que se ensina nos departamentos universitários), mas também, em muitos casos, por um efeito de alheamento (a filosofia tal qual se produz pode ser antagónica da filosofia que se ensina no contexto da Universidade).

Em Portugal, entre a década de 30 e a década de 60, em que Eduardo Abranches de Soveral apresenta a sua dissertação de doutoramento sobre O Método Fenomenológico, a situação é ainda mais complexa. Para lá dos traços deixados por algumas figuras que as circunstâncias políticas tornam obviamente pensadores isolados, como é o caso de Vasco Magalhães Vilhena ou Egídio Namorado, para lá ainda das marcas deixadas por alguns conhecedores competentes e criativos do neopositivismo e da lógica simbólica, como Delfim Santos e Edmundo Curvelo, por exemplo, ou ainda da obra singular de Eduardo Lourenço, em Heterodoxias (1949), ou do longo magistério de 
Vieira de Almeida, o espaço público da produção e discussão de ideias está muito marcado pela escola da filosofia portuguesa, tal como ela se viria a constituir por referência ao movimento da Renascença Portuguesa depois da saída de António Sérgio e de Raul Proença. Além da figura de referência de Leonardo Coimbra - fundador, diretor e professor da Faculdade de Letras da Universidade do Porto de que Eduardo Abranches de Soveral foi uma espécie de "segundo fundador" no que aos estudos filosóficos diz respeito -, nele pontificavam vultos como Álvaro Ribeiro, Sant'Anna Dionísio, José Marinho, António Quadros, Afonso Botelho, e outros. Ora se há algo que caracterize o ideário deste movimento (não considerando aqui o seu vulto tutelar, Leonardo Coimbra, intelectual de múltiplos interesses e bom conhecedor da atualidade filosófica e cientifica de além-fronteiras) é precisamente a tentativa de reconstituir uma especificidade da "cultura portuguesa", indo surpreendê-la nos textos literários e poéticos, ou nos usos e costumes ancestrais. Tratar-se-ia sobretudo de obra de hermeneuta. Haveria que saber ler e interpretar. Em nossa opinião, esta atividade era largamente performativa: o rosto da cultura portuguesa estava sendo criado no próprio ato que supostamente o descrevia - não era a cultura que se alcandorava à filosofia, qual consciência final de si mesma; era antes uma certa filosofia que desenhava a cultura que, por sua vez, a justificava. Não é, porém, este processo sinuoso de escolha, em que algo se elege e algo se elimina, que me interessa. Interessa-me apenas salientar que, determinada pelas ideias deste movimento, a filosofia tal como se produzia no espaço público estava não só em divórcio deliberado (que não era desconhecimento) com a atualidade filosófica de outras paragens da Europa e do Mundo, como também, por extensão, com a atividade filosófica universitária que, se bem que retardada relativamente à atualidade, dava voz, por dever de ofício, à tradição que essa filosofia recusa como alheia à especificidade do génio nacional. Assim, a situação tornava-se, como dissemos, bastante mais complexa. A filosofia universitária estava, então, alheada do que era talvez a força mais estuante da Filosofia portuguesa da atualidade, e essa filosofia da atualidade estava, por sua vez, largamente em rotura com a cultura filosófica hodierna de além-fronteiras, que a filosofia universitária ia assimilando com um efeito natural de retardamento.

Assim, não admira que autores como Husserl, Scheler, Sartre, MerleauPonty, Levinas, ou também, para olhar numa outra direção, Russell, Moore, Wittgenstein, Schlick ou Carnap, se bem que direta ou indiretamente conhecidos, não tenham, porém, uma presença determinante nem na filosofia do espaço público nem na filosofia universitária, quer por um efeito de alheamento (e antagonismo, mesmo), quer por um efeito de retardamento. E não admira também que, descontado os casos de Cabral de Moncada e de Brandão, e ainda de outro que adiante veremos com detença, seja apenas nos 
anos 60 que a fenomenologia, tanto na versão husserliana como na heideggeriana, chegue consistentemente ao ensino universitário de filosofia. Na verdade, há uma aparição episódica da Fenomenologia nos anos 40 , por via de Diamantino Martins ${ }^{1}$ e de Severiano Tavares, ${ }^{2}$ na então recentíssima Revista Portuguesa de Filosofia, fundada em 1945. Todavia, a fenomenologia só é assumida como uma referência consistente nos trabalhos de Cabral de Moncada, da Universidade de Coimbra, dedicados à filosofia do direito, nomeadamente na Filosofia do Direito e do Estado, de 1947, e na conferência de 1945 “A Caminho de um Novo Direito Natural", publicada em 1958. ${ }^{3}$ Aliás, uma outra presença da fenomenologia, nestes anos iniciais, também ela na área da filosofia do direito, presença apesar de tudo menos decisiva que a de Cabral de Moncada, é devida à obra de António José Brandão. ${ }^{4}$ Esta surpreendente eficácia da fenomenologia em pensadores da área jurídica, ainda anterior à sua aparição consistente nos cursos universitários de filosofia pura, explica-se pela circunstância de, apesar de a filosofia do direito não pertencer ao núcleo do pensamento de Husserl, de Scheler ou de Heidegger, um escol de fenomenólogos ter produzido trabalho teórico de extrema relevância nessa área. Logo em 1913, tinha sido o caso de Adolf Reinach e, a partir dos anos 20, tinha sido o caso de Fritz Schreier e Felix Kaufmann, muito próximos do positivismo jurídico de Kelsen, e, nas décadas subsequentes, seria também o caso de Gerhart Husserl, filho do próprio fundador da fenomenologia, e de Carlos Cossio, mais uma vez em confrontação muito direta com Kelsen. Excetuado, portanto, esta incorporação precoce, em Portugal, da fenome-

${ }^{1}$ Diamantino Martins, "Fenomenologia e imortalidade". Revista Portuguesa de Filosofia, 2, 1946.

${ }^{2}$ Severiano Tavares, "Os Arquivos de Husserl". Revista Portuguesa de Filosofia, 2, 1946.

${ }^{3}$ Para sermos rigorosos, porém, só no segundo volume de Filosofia do Direito e do Estado, publicado em 1965, fala Moncada especificamente da Fenomenologia. A conferência, proferida em Madrid, sobre o Direito Natural seria publicada em Estudos filosóficos e Históricos. Artigos, Discursos, Conferências e recensões Críticas. - Acta Universitatis Conimbrigensis, vol. I. Coimbra: Universidade de Coimbra, 1958. Para lá destas obras, há continuada presença da Fenomenologia na série "Sobre Epistemologia Jurídica", publicada no Boletim da Faculdade de Direito de Coimbra, XXIV, XXVI e XXVII, entre 1948 e 1952 . A confrontação da Teoria Egológica do Direito, do argentino Carlos Cossio, fenomenólogo que se inspira tanto em Husserl como em Heidegger, com o Positivismo Jurídico de Kelsen é outro dos vectores pelos quais passa a Fenomenologia na obra de Cabral de Moncada.

${ }^{4}$ De António José Brandão, veja-se O Direito. Ensaio de Ontologia Juridica. Lisboa, 1942 (Dissertação de Doutoramento não aprovada, onde se refere autores como Reinach, Husserl ou Heidegger.); "A Caminho de um novo Direito Natural?". Revista Portuguesa de Filosofia, 1 (1945); "A Teoria Egológica do Direito". Boletim da Faculdade de Direito de Coimbra, XXI (1946); "A Fenomenologia da Sentença". Boletim do Ministério da Justiça, 2 (setembro de 1947); "Vigência e Temporalidade do Direito". Boletim da Faculdade de Direito de Coimbra, XIX (1943) e XX (1944). 
nologia no trabalho teórico inovador, por via da filosofia do direito, com Brandão e sobretudo Moncada, a primeira presença significativa e continuada da fenomenologia revestirá, como disse, a forma de estudos académicos de interpretação a partir dos anos 60 , relativos a um corpus teórico já largamente concluído e de onde já se tinha retirado a chama viva do trabalho inovador. Foram referências insignes desta incorporação da fenomenologia no contexto universitário, por via da interpretação e do comentário, figuras como Júlio Fragata (cuja tese de doutoramento é de 19595), de Braga, ou Alexandre Morujão (tese de doutoramento em $1961^{6}$ ) e Gustavo de Fraga (tese em 1966 $)$, ambos docentes na Universidade de Coimbra.

\section{II}

Relativamente a estes distintos e muito competentes intérpretes da Fenomenologia de Husserl, Heidegger ou Scheler, que dominam a língua original e que têm, além disso, um conhecimento alargado do corpo textual, mesmo, em certos casos, do ainda inédito, por força da frequência de bibliotecas e arquivos pela Europa, a primeira obra de Eduardo de Abranches Soveral que trata extensivamente da fenomenologia tem uma feição assaz diferente. ${ }^{8}$ Na verdade, em $O$ Método Fenomenológico. Estudo para a Determinação do seu Valor Filosófico, de 1965, de que só a primeira parte está publicada, sobre $O$ Valor do Método para a Filosofia, nem o conhecimento das obras é direto, mas dependente de traduções, como o próprio, aliás, declara no Prólogo, ${ }^{9}$ nem o objetivo é interpretar, mas antes discutir e avaliar. Dir-se-ia que, onde a competência minuciosa e árdua do intérprete está ausente, para a qual os textos, na sua positividade, são uma espécie de ultima ratio, está presente a ousadia

5 Júlio Fragata, A Fenomenologia de Husserl como Fundamento da Filosofia. Braga: Livraria Cruz, 1959.

${ }^{6}$ Alexandre Fradique Morujão, Mundo e Intencionalidade. Ensaio sobre o Conceito de Mundo na Fenomenologia de Husserl. Coimbra: Universidade de Coimbra, 1961. A. Morujão publicara já a sua tese de licenciatura, intitulada $A$ Doutrina da Intencionalidade na Fenomenologia de Husserl. Das Investigações Lógicas às Meditações Cartesianas. Coimbra (separata de Biblos, XX), 1951.

${ }^{7}$ Gustavo de Fraga, De Husserl a Heidegger: Elementos para uma Problemática da Fenomenologia. Coimbra: Universidade de Coimbra, 1966.

${ }^{8}$ Antes, Eduardo Soveral havia publicado cerca de oito artigos, entre 1949 ("Primeira reflexão sobre o problema do escol", Cidade Nova, 2, Coimbra) e 1964 ("Perspetivas cristãs da cultura", separata da coletânea Encontro de Universidades Católicas, Porto), mas nenhum deles sobre questões de natureza fenomenológica.

${ }^{9}$ Ver Eduardo Soveral, O Método Fenomenológico. Estudo para a Determinação do seu Valor Filosófico, 1. Valor do Método para a Filosofia. Porto, 1965, p. 11 
máxima do pensador que se quer original e que não hesita em correr os riscos daí decorrentes.

Esta postura do pensador e não apenas e simplesmente do intérprete determina todo o diálogo de Eduardo Soveral com a fenomenologia. É por isso que certas assimilações de conceitos fenomenológicos nucleares que, do ponto de vista da fidelidade textual, seriam suscetiveis de reparos, se constituem, antes, como outras tantas redefinições desses conceitos, algumas delas não inteiramente conscientes, e valem como expressões de um pensamento original que se vai progressivamente desenhando. É caso bem visível desta assimilação criativa o modo como Eduardo Soveral caracteriza conceitos tão centrais na fenomenologia como os de epoché, de plano transcendental, de experiência, de transcendência e até mesmo de fenómeno puro.

O diálogo de Eduardo Soveral com a fenomenologia não é, portanto, o do simples comentador ou intérprete. É, antes, o do pensador que dela se apropria para as suas próprias conceções. Ora quando nos interrogamos sobre a origem do questionário que Soveral dirige à fenomenologia, bem como sobre o modo como a compreende, a ela e aos seus conceitos fundamentais, é a seu mestre de Coimbra, Arnaldo Miranda Barbosa, que somos reconduzidos. De fato, a entrada da fenomenologia no universo intelectual de Soveral visa responder a um conjunto de problemas que foram hauridos não na própria fenomenologia, mas antes nas posições que Miranda Barbosa defende na sua tese de 1945, publicada em 1947, intitulada A Essência do Conhecimento. ${ }^{10}$

Essa obra - de um brilhantismo raro, aliás - está dividida numa Analítica e numa Dialética. A analogia com a divisão kantiana da Crítica da Razão Pura é, porém, enganadora. Primeiro, porque a Analítica não está precedida (nem é sucedida) por uma Estética, ou seja, por uma teoria da intuição que mostre a ancoragem dos conceitos nos dados da experiência pura ou empírica; segundo, porque o próprio conceito de Analítica se define, para Miranda Barbosa, não como uma Lógica da Verdade, à maneira kantiana (mas também de Aristóteles), e sim como uma Análise Lógica dos Pensamentos, análise que é, no seu fundo, uma espécie de semântica formal, que define o que se entende por conceito, por conteúdo objetivo, por conceito geral e individual, por ideosfera, etc. dando para tudo isso as fórmulas atómicas correspondentes; terceiro, porque a própria Dialética não é, ao modo kantiano (e, mais uma vez, ao modo aristotélico dos Tópicos e das Refutações Sofisticas), uma doutrina da aparência de verdade, mas visa levantar e responder argumentativamente ao que Miranda Barbosa define como o Problema Essencial do Conhecimento. É justamente

${ }^{10}$ Ver Arnaldo de Miranda Barbosa, Obras Filosóficas. Lisboa: Imprensa Nacional-Casa da Moeda, pp. 221-385. 
por isso que a Dialética não tem que ver com as disciplinas da Metafísica Especial, como em Kant, mas se divide, antes, numa Aporemática, que levanta o Problema Essencial do Conhecimento, numa Aporia, que mostra as dificuldades da resposta idealista, e numa Euporia, que apresenta o Realismo como a única solução possível para o problema. A obra, de grande vigor intelectual, é, em suma, na parte analítica, uma teoria do conceito e da relação do conceito com um objeto através de um conteúdo, teoria para a qual Miranda Barbosa usa, de um modo assaz indisciplinado, instrumentos conceptuais da Teoria dos Conjuntos, operadores booleanos como a soma e o produto lógico (fazendo equivaler erradamente o produto lógico de dois conjuntos, a intersecção, com o operador lógico da conjunção), e noções do Cálculo Integral, como a de limite e de série convergente, cuja aplicação à esfera conceptual será altamente controversa; na sua segunda parte, a obra consiste numa tentativa de solução dialética da controvérsia entre Realismo e Idealismo, demonstrando ser o primeiro a única hipótese à luz da qual o Problema Essencial do Conhecimento pode receber uma solução plenamente satisfatória.

Como Miranda Barbosa expressamente o formula na primeira parte da Dialética, na 4. ' Definição, "O problema essencial do conhecimento consiste em indagar o que é o conhecimento, q. d., em investigar se o conhecimento é ou não aquilo que no fenómeno do conhecimento parece intencionalmente ser"."

Um breve comentário dos pressupostos deste problema será, aqui, necessário, pois é ele que fornece a Eduardo de Soveral o horizonte problemático para o seu diálogo com a Fenomenologia.

Há, para Miranda Barbosa, algumas ideias que lhe parecem tão óbvias que, ao serem por ele apresentadas, não são nunca objeto de uma expressa discussão. A primeira é que aquilo a que chama lógica - mas que é mais uma semântica formal do que aquilo que hoje em dia se entende por esse nome - pode mostrar que os conceitos se referem a objetos, mas já não pode demonstrar que existem os objetos a que os conceitos se referem. Isso é uma verdade inquestionável, dado que essa referência é uma relação intencional e a intencionalidade é definida precisamente como uma relação não-real. De fato, para Miranda Barbosa, a relação de um conteúdo conceptual com o objeto referido por meio desse conteúdo é uma relação intencional que faz parte da estrutura atómica do conceito e que é independente da existência do objeto. Mesmo que, num sentido ontológico-metafísico, não houvesse nenhuma realidade independente, os conceitos continuariam a ter conteúdo e, através desse conteúdo, referir-se-iam a objetos. Ou seja, a lógica não

${ }^{11}$ Miranda Barbosa, ob. cit., p. 331. 
resolve, mas antes levanta um problema gnosiológico. Nas suas palavras, "a pura análise do objeto formal [...] nunca permitirá provar a existência dos entes. A única nota que poderá assegurar existência seria a 'referência intencional' do conceito ao objeto, mas, precisamente porque essa referência é 'intencional', não dá garantia de transcendência real à esfera objetiva". ${ }^{12}$ No entanto, este problema gnosiológico, que Miranda Barbosa apelida de essencial, parece estar, por sua vez, dependente de uma noção ontológico-metafísica nunca discutida e justificada, justamente o conceito de Realidade como existência independente de qualquer relação com uma subjetividade cognoscente. Esta dependência do problema gnosiológico fundamental relativamente a um conceito metafísico de Realidade, como existência absolutamente transcendente ou "em si", atua em Miranda Barbosa como um pressuposto implícito na sua formulação do Problema Essencial do Conhecimento.

A segunda ideia, conexa com a primeira, é que a atitude transcendental é provisória e insuficiente. Na verdade, a atitude transcendental, para Miranda Barbosa, consiste não na produção de um novo conceito de objetividade que supere a velha querela do Realismo e do Idealismo, mas apenas num dispositivo metódico para analisar e descrever a conexão entre pensamento e objetividade pensada, deixando ainda indecidido o estatuto ontológico do objeto. Assim, para Miranda Barbosa, esta atitude não é resposta (e uma resposta de tipo novo), mas antes suspensão do Problema Essencial do Conhecimento. Ela é, por isso, um procedimento inteiramente correto tanto quanto nos movamos no quadro de uma análise semântica sobre a conexão entre conteúdo significativo e objetividade significada através desse conteúdo. No entanto, quando a lógica dá lugar à gnosiologia, a posição transcendental, com a sua neutralidade relativamente ao estatuto ontológico da objetividade, é imediatamente superada. Miranda Barbosa di-lo num passo de A Essência do Conhecimento com a sua clareza costumeira: "A posição do objeto relativamente ao pensamento poderá determiná-lo como imanente, transcendente ou transcendental. [...] Estabelecer o problema da essência do conhecimento parece não ser mais do que formular esta pergunta - qual dessas posições ocupa o objeto em relação ao pensamento? Porém, logo se vê que a hipótese transcendental está imediatamente eliminada [...]. Com efeito, a posição transcendental do objeto é já um mínimo lógico fornecido pelo fenómeno cognitivo e esse dado é que desperta a dúvida da imanência ou transcendência do objeto. [...] Chamar transcendental ao objeto não é mais do que suspender o juízo sobre a sua transcendência, e o que se pretende afastar da gnosiologia é precisamente

${ }^{12}$ Miranda Barbosa, ob. cit., p. 339, ver também p. 340. 
esta indeterminação lógica, concluindo se o objeto é imanente ou transcendente, por outras palavras - se o objeto existe ou não existe". ${ }^{13}$

A terceira ideia é que há lugar para distinguir, a propósito do fenómeno do conhecimento, entre questões descritivas e questões substantivas. De facto, o fenómeno do conhecimento parece ser a captação de uma realidade exterior à atividade que a visa e capta, ou seja, uma realidade transcendente. Mas será efetivamente assim ou teremos de classificar isso como uma ilusão, mostrando que o objeto que, no conhecimento, se nos depara como transcendente é, na realidade, imanente ao ato de conhecer e existe apenas como correlato desse ato? Em suma, a descrição do fenómeno do conhecimento segundo o seu sentido interno não dará qualquer resposta à pergunta sobre a existência de um plano de objetualidade exterior e independente da atividade cognitiva. Tais são os problemas que, para Miranda Barbosa, faz sentido contrapor às questões meramente descritivas. E é justamente na fusão destas duas ordens de problemas, ou melhor, na crença de que as questões descritivas esgotam as questões substantivas, que Miranda Barbosa julga ver o grande erro da fenomenologia: "É neste ponto que Edmundo Husserl e todos os seus discípulos muito erraram, supondo que descrever é resolver e considerando que a descrição do fenómeno é já a solução do problema essencial que nele reside". ${ }^{14}$

Miranda Barbosa, na sua tese de 1945, é, assim, ao lado de Cabral de Moncada e de António Brandão, mas já na área da Filosofia pura, o primeiro a incorporar no seu trabalho criativo uma discussão aprofundada com a escola fenomenológica, particularmente a provinda da obra de Edmund Husserl. A sua posição de fundo relativamente à fenomenologia é, também, claríssima e fácil de sumariar nos três pontos seguintes:

1.') A negação de fundamentalidade. A disciplina fundamental da filosofia é uma semântica formal (uma "lógica"), que descreve a estrutura atómica dos conceitos e a relação intencional entre conteúdo de pensamento e objetividade pensada, sem tomar qualquer posição sobre o problema essencial do conhecimento. Nas suas palavras, a disciplina filosófica fundamental é a lógica e não a fenomenologia..$^{15}$

${ }^{13}$ Miranda Barbosa, ob. cit., p. 341.

${ }^{14}$ Ibid., p. 331.

15 "A análise lógica dos pensamentos aparece como inteiramente livre de pressupostos, como propedêtica a qualquer investigação gnosiológica, reivindicando a qualidade de disciplina filosófica fundamental que Edmundo Husserl, ao renovar a aspiração cartesiana, atribuíra à Fenomenologia". Ibid., p. 338. 
$2^{\circ} .^{\circ}$ A denúncia de um equívoco. A descrição fenomenológica do conhecimento fixa-se no plano transcendental e na relação intencional entre conteúdo e objeto visado, não podendo, por isso mesmo, ser uma resposta cabal ao problema gnosiológico essencial - ou seja, como método transcendental de investigação, a fenomenologia deve revestir a forma de uma lógica, enquanto análise pura dos pensamentos, e deve perder a ambição de se apresentar como uma verdadeira gnosiologia. ${ }^{16}$

3.') A atribuição de uma incapacidade. Devido à sua orientação metodológica, que faz da descrição do sentido dos atos o seu procedimento basilar, a fenomenologia não permite formular o problema fundamental da existência ou não existência real do objeto de conhecimento, limitando-se a tratar o objeto como correlato de um ato intencional e a estabelecer leis de essência (eidéticas) sobre essa correlação noético-noemática, de tal modo que a fenomenologia, com base nessa sua orientação de fundo, no próprio momento em que julga ter descrito as leis de essência do conhecimento, estará apenas a patentear a sua incapacidade para dizer o que o conhecimento efetivamente é, por se confinar tematicamente à análise da vivência de conhecimento e, por isso mesmo, à simples descrição daquilo que ele parece ser. ${ }^{17}$

\section{III}

Dezoito anos após a publicação do livro de Miranda Barbosa, Eduardo Soveral escreverá no seu livro $O$ Método Fenomenológico, referindo-se ao Problema Essencial do Conhecimento, o seguinte: "Estas nossas considerações [videlicet, as expendidas nessa sua obra] visam, em última análise, uma determinação do valor filosófico do método fenomenológico à luz desta problemática [ou seja, à luz do Problema Essencial do Conhecimento]". ${ }^{18}$

16 “[...] Se a Fenomenologia é apenas um método de investigação transcendental, é legítima enquanto se mantém na descrição dos fenómenos noemáticos, mas torna-se viciosa sempre que se transforma em sistema de explicação, sem previamente se ter resolvido o problema que a referida distinção envolve, porque na cogitatio husserliana a intencionalidade não obstante as origens históricas do termo) é apenas transcendental, no sentido kantiano da expressão". Ibid., p. 340.

17 "É óbvio que a discussão do problema essencial do conhecimento há-de tocar necessariamente na questão ontológica da existência do objeto, pois só demonstrando se o objeto existe ou não existe se poderá saber o que é o conhecimento que intencionalmente lhe reportamos [...]". Ibid., p. 347 .

${ }^{18}$ Eduardo Soveral, O Método Fenomenológico. Estudo para a Determinação do seu Valor Filosófico, 1. Valor do Método para a Filosofia, ed. cit., p. 156. 
Não poderia ser mais clara a afirmação de que o diálogo com a fenomenologia está inteiramente determinado pelas questões levantadas por Miranda Barbosa. São precisamente essas questões que dão sentido - e, diga-se, um sentido não-fenomenológico - à reformulação de Eduardo Soveral do Problema Essencial do Conhecimento, a qual se faz, porém, aparentemente, por meio de alguns conceitos fenomenológicos nucleares. Essa reformulação reza assim:

O problema essencial do conhecimento [...] consiste em saber se o objeto intencional a que todo o conhecimento se reporta é ou não imanente ao sujeito que o pensa. ${ }^{19}$

Dir-se-ia que, comparada esta formulação com a de Miranda Barbosa, tudo é agora dito e caracterizado a partir do aparato conceptual da fenomenologia, nomeadamente, a partir dos conceitos de "ser imanente" e de "realidade transcendente", se bem que Miranda Barbosa já os tivesse usado num sentido puramente ontológico. No entanto, que haja aqui uma reformulação fenomenológica do problema é uma asserção que não é inteiramente exata, pois, como Miranda Barbosa bem vira, o Problema Essencial do Conhecimento não é fenomenologicamente enunciável. De fato, do ponto de vista da fenomenologia, ele é um pseudo-problema, e, do ponto de vista de Miranda Barbosa, ele é o verdadeiro problema em torno do qual toda a gnosiologia deve gravitar. Abranches Soveral tem uma consciência aguda desta relação tensional da fenomenologia - primacialmente, a husserliana - com o Problema Essencial do Conhecimento. A sua forma de resolver essa tensão consiste em distinguir três zonas na fenomenologia: a primeira, onde "o problema essencial do conhecimento não é inicialmente considerado", a segunda, onde "se considera que o problema essencial do conhecimento foi superado e já não tem sentido no plano transcendental", e a terceira, finalmente, "em que a redução transcendental não é praticada", mas em que, por outro, "são levadas em linha de conta as exigências metódicas do problema essencial do conhecimento". ${ }^{20}$ A primeira zona diz respeito à fenomenologia eidética, que teve nos fenomenólogos de Munique a sua máxima expressão. A segunda é, para Abranches de Soveral, a zona onde se inserem não só a fenomenologia transcendental dos períodos de Gotinga e de Friburgo, como também a obra de Heidegger e das "grandes figuras da chamada fenomenologia existencialista". ${ }^{21}$ Para a terceira, que seria a zona da fenomenologia mais afeiçoada para um diálogo expresso

\footnotetext{
${ }^{19}$ Ibid., p. 33, nota 24; ver também p. 47.

${ }^{20}$ Ibid., pp. 37-38.

${ }^{21}$ Ibid., p. 39.
} 
com as questões gnosiológicas provindas de Miranda Barbosa, Abranches de Soveral, paradoxal ou sintomaticamente, reconhece que, sendo uma zona pertencente à "etapa inicial" da fenomenologia, mas não se confundindo, todavia, com a fenomenologia eidética, terá na obra não de Husserl e sim de Nicolai Hartmann o seu principal representante. ${ }^{22}$ Tudo se passa, portanto, como se o Problema Essencial do Conhecimento não conhecesse outro ponto de intersecção com a fenomenologia senão na obra de um autor como N. Hartmann, que usa a fenomenologia no quadro mais lato de uma metafísica do conhecimento alheia à fenomenologia sensu stricto.

Assim, a tentativa de trazer para dentro da fenomenologia o Problema Essencial do Conhecimento exige a Abranches Soveral uma dupla tarefa - que ele assume expressamente - de reformulação inovadora desse problema, quer relativamente a Miranda Barbosa, onde o vai haurir, quer relativamente à própria fenomenologia, para onde o pretende trasladar.

Uma breve análise da reformulação de Soveral, acima transcrita, pode mostrá-lo imediatamente. Primeiro, relativamente a Miranda Barbosa, o acento não é já posto no pensamento e na relação do pensamento com o seu objeto, como Miranda Barbosa o fizera, usando, aliás, o conceito de "pensamento" num sentido não-psicológico, mas lógico-semântico, que se aproxima das teorias de Frege e de Husserl sobre der Gedanke ou die ideale Bedeutung como der Sinn eines Satzes, ou das conceções de Bolzano sobre o Satz e a Vorstellung an sich; pelo contrário, o acento é, agora, posto no sujeito e no seu ato, num sentido psicológico e real. Soveral não pergunta, como Barbosa, se o conhecimento é o que parece ser, mas se o objeto é imanente ao sujeito que o pensa. Esta mudança não é sem importância, pois dá uma conotação subjetivo-existencial a uma problemática que, em Miranda Barbosa, era estritamente lógico-gnosiológica. Essa diferença é assumida pelo próprio Soveral numa longa nota em que se explica relativamente a seu mestre. Diz: "nós relacionamos a imanência e a transcendência do objeto com o sujeito do conhecimento; o Prof. Miranda Barbosa refere uma e outra ao próprio pensamento". Isto implica, aos olhos de Soveral, que o Problema Essencial do Conhecimento tenha uma génese a partir da contraposição vivida do eu com o mundo e não da simples descrição do fenómeno de conhecimento. Voltaremos a este ponto.

Em segundo lugar, olhando agora na direção da fenomenologia husserliana, não é ajustado dizer que o conhecimento se reporta a um "objeto intencional". Reporta-se intencionalmente a um objeto, ou seja, reporta-se a um objeto através de uma significação (Bedeutung), de um sentido (Sinn) ou de um noema, tudo caracterizações que, se bem que ligeiramente diferentes,

${ }^{22}$ Ibid., p. 40. 
são sobreponíveis. Se viso a Lua, é a própria Lua que é o objeto intencional do meu ato, e não uma micro-Lua na consciência, ou uma imagem da Lua, ou uma sua "ideia" que fosse o terminus ad quem da intenção, à maneira supostamente cartesiana. ${ }^{23}$ A tentativa de Miranda Barbosa, seguida por seu discípulo Abranches Soveral, de mostrar que Descartes, com a sua teoria das ideias, é o originador do Problema Essencial do Conhecimento, não torna automaticamente a fenomenologia, por via do seu "cartesianismo", vítima das mesmas dificuldades em que se afundou o cartesianismo histórico. É certo que o conceito ambíguo de Brentano da "inexistência intencional" do objeto no ato, ${ }^{24}$ ou as doutrinas de Kazimierz Twardowski sobre a dupla objetividade, ${ }^{25}$ bastante mais próximas de Husserl, faziam com que posições deste tipo se tornassem possíveis. Mas uma característica da posição de Husserl é a declaração expressa de que objeto intencional e objeto real são apenas um. ${ }^{26}$ Portanto, a pergunta sobre se micro-objetos como luas, cães ou árvores estão no sujeito que os pensa não é obviamente uma pergunta com sentido para uma teoria que, como a fenomenologia, desde as Investigações Lógicas recusou a ideia de que os objetos intencionais dos atos são imagens na consciência, que por sua vez se reportam (ou não) a objetos extra-mentais. Acresce que esta relação intencional com um objeto através de um conteúdo significativo (um noema) não pode ser ainda descrita como uma vivência de conhecimento. Trata-se do simples visar (meinen), que pode ser completamente vazio, tal como quando falamos da face oculta da Lua, sabemos a que objeto nos referimos com essa significação, mas não encontramos nenhuma intuição que nos ponha diante dos olhos a própria coisa a que nos referimos. Portanto,

${ }^{23}$ Sérias dúvidas podem ser levantadas acerca desta interpretação tradicional de Descartes, que Miranda Barbosa e Abranches de Soveral subscrevem, segundo a qual a idea é não o terminus a quo, mas o terminus ad quem do conhecimento. A razão tradicional que se invoca para esta leitura é que só se a ideia for o termo do conhecimento é que algo como uma dúvida a respeito da "realidade exterior" (ou seja: do ideado) será possível. Para uma interpretação completamente diversa desta questão, ver o meu Subjetividade e Tempo na Fenomenologia de Edmund Husserl. Lisboa: Centro de Filosofia da Universidade de Lisboa, 2002, p. 341 e ss.

24 "Jedes psychische Phänomen ist durch das charakterisiert, was die Scholastiker des Mittelalters die intentionale (auch wohl mentale) Inexistenz eines Gegenstand gennant haben [...]." Franz Brentano, Psychologie vom empirischen Standpunkt. Leipzig: Duncker \& Humbolt, 1874, Buch 2, Kap. I, 5, 20. A palavra "inexistência" (Inexistenz) não significa "não-existência", mas sim "existência-em", a saber, no fenómeno psíquico ou ato.

${ }^{25}$ Kazimierz Twardowski, Zur Lehre vom Inhalt und Gegenstand der Vorstellungen: Eine Psychologische Untersuchung. Wien: Philosophia, 1894.

${ }^{26}$ Husserl di-lo perentoriamente em Logische Untersuchungen, no Apêndice aos $\$ \S 11$ e 20 , num célebre texto, que Abranches de Soveral não podia desconhecer, intitulado "Para a crítica da Teoria das Imagens e da doutrina dos objectos imanentes aos actos", nomeadamente em Hua XIX/1, 439. Aliás, as posições de Twardowski foram expressamente criticadas por Husserl numa recensão de que Soveral não teria tido, certamente, conhecimento. 
a boa lição fenomenológica é que visar um objeto (Meinung) não é ainda conhecimento (Erkenntnis) desse objeto. A intencionalidade, só por si, não é ainda conhecimento. Para que o conhecimento se realize, é necessário que se produza uma síntese entre um ato que visa e um ato que dá intuitivamente a objetividade visada, e tal como é visada. Só este preenchimento (Erfüllung) da intenção significativa pelo ato intuitivo é efetivamente conhecimento. Não é exato, pois, dizer que o conhecimento se reporta a um objeto intencional. $O$ conhecimento é, antes, uma síntese de preenchimento pela qual o ato intuitivo dá o objeto a que o ato signitivo intencionalmente se reporta. Por fim, a questão melindrosa é que não tem um sentido fenomenológico pertinente perguntar se o objeto visado é ou não imanente ao sujeito que o pensa. Como foi dito, o objeto intencional não é um micro-objeto na consciência, é a consciência de um objeto transcendente ou o objeto transcendente tal como é visado. Se viso a face oculta da Lua, o objeto intencional desse ato é a Lua na sua face oculta, ou seja, a própria Lua, enquanto visada através de um sentido, é o objeto intencional do ato. Em boa disciplina fenomenológica, distingue-se, portanto, o objeto tal como é visado (Gegenstand im Wie), a Lua na sua face oculta, e o objeto puro e simples, que é visado (Gegenstand schlechtin), a própria Lua enquanto tal, que é o pólo $X$ de unificação de vários "objetos-no-como" ou, como Husserl também diz, de vários noemas-predicado. No entanto, não tem sentido fenomenológico pertinente perguntar se este objeto, seja o objeto tal como é visado, seja o objeto que é visado, são ou não imanentes ao sujeito que os pensa. A resposta é, obviamente, um claro não. Um e outro dão-se como transcendentes tanto ao ato que os visa aqui e agora como a qualquer outro ato que os possa visar em qualquer outro momento ou circunstância. O que é, de fato, imanente é o sentido de apreensão ou noema. Mas o noema não é o objeto, é o conteúdo sintático e semântico através do qual há consciência de um objeto. Mesmo para este noema, que é uma unidade ideal e sempre repetível em atos diversos, a sua imanência é, todavia, uma imanência intencional e não real, ou seja, ele não é um ingrediente do próprio ato intencional, mas um elemento construtor da consciência de objeto, como Husserl o explica, aliás, desde A Ideia de Fenomenologia. Cinco Lições, de 1907.27

Bem se vê que, mesmo quando revestido com os conceitos fenomenológicos de intencionalidade, imanência e transcendência, o Problema Essencial do Conhecimento permanece um problema só formulável quando se rebate sobre a fenomenologia um questionário que the é exterior. Perguntar fenomenologicamente se o objeto visado é real não significa perguntar se ele apenas

27 Ver Die Idee der Phänomenologie. Fünf Vorlesungen, Hua II, passim. 
parece ser real ou se o é efetivamente, não significa também perguntar se ele é imanente ao sujeito que o pensa, significa, outrossim, perguntar se e como, à consciência que o visa, pertence ou não um ato de crença que põe esse objeto numa consciência de realidade, e se essa crença é ou não racionalmente justificável na evidência correspondente. Não cabe perguntar se, por detrás da realidade revestida pelo sentido das minhas intenções, há ainda uma realidade em si que lhe seja semelhante. A Realidade é o objeto da consciência de realidade. De um conceito de Realidade absoluta, independente de qualquer relação com uma intencionalidade que a vise; de uma Realidade para ninguém (ou para o olhar sem ponto de vista de Deus), não tem a fenomenologia a mínima notícia. Como Husserl bastas vez o disse, o conceito de uma existência "em si", sem relação com uma consciência para a qual ela seja justamente isso, é um Unsinn, um conceito sem sentido. O problema que aqui se lança à fenomenologia é, pois, um problema extra fenomenológico. E é precisamente nesta distância, originalmente cavada por Miranda Barbosa, que se espraia o pensamento inovador de Eduardo Soveral.

\section{IV}

Não seria possível fazer um resumo do pensamento fenomenológico de Eduardo Abranches de Soveral. Mas será, todavia, oportuno não só mostrar como ele se interna na fenomenologia a partir do questionário prévio que acabamos de apresentar, como também reconstituir a sua trajetória global.

Desde logo, há, contra Miranda Barbosa, uma clara reivindicação da fundamentalidade da gnosiologia e não da lógica. Contrapondo-se às teses de fundo de seu mestre, Eduardo Soveral sustenta não ser a lógica pura, mas sim a gnosiologia que se constitui como "primeira disciplina filosófica", na medida em que será essencialmente gnosiológica a atitude metódica e a problemática que despontam de uma assunção radical da atitude filosófica: "a atitude filosófica [...] é predominantemente gnosiológica". ${ }^{28}$ Objetando a seu mestre que há um dédalo em estabelecer, por um lado, que a lógica não deve admitir pressupostos gnosiológicos e, de seguida, chamá-la a resolver o Problema Essencial do Conhecimento, objetando ainda que a própria lógica pura impõe, ou supõe já, "certas formas de conhecimento" e, portanto, uma decisão preliminar "para além da mera e prévia determinação de qual seja a

${ }^{28}$ Eduardo Soveral, $O$ Método Fenomenológico. Estudo para a Determinação do seu Valor Filosófico, 1. Valor do Método para a Filosofia, ed. cit., p. 97. 
sua essência", ${ }^{29}$ Eduardo Soveral sustenta que a "posição cartesiana [...], do mesmo modo que a epoche de Husserl, permitem evitar que a solução do problema essencial do conhecimento, inicial na ordem dos fundamentos, tenha de ser dogmaticamente afirmada, possibilitando, para o efeito, a constituição de um campo gnósico sui generis em que o mesmo problema pode ficar justificadamente em aberto". ${ }^{30} \mathrm{O}$ campo da gnosiologia abre-se, assim, para Eduardo Soveral, como o lugar de uma investigação que permanece prévia a qualquer tomada de posição ontológica e a condiciona, nomeadamente ao propiciar a solução do Problema Essencial do Conhecimento na direção do Realismo ou do Idealismo não de uma forma Dialética, como em Miranda Barbosa, mas por uma descrição do próprio sujeito de conhecimento e da sua relação com os seus objetos de onde se retirem indícios para uma subsequente determinação ontológica do seu estatuto. Como veremos, Soveral julga encontrar esses indícios ao reconduzir a descrição da estrutura em horizonte da objetividade para a finitude da subjetividade e desta, outra vez, para a transcendência do objeto relativamente ao sujeito que o experiencia.

Para uma boa compreensão do modo como a reflexão de Soveral sobre o Problema Essencial do Conhecimento se encontra com a descrição fenomenológica da vivência de conhecimento, há que recuar um pouco e reconstituir o que é, para ele, a verdadeira fonte do filosofar. Mais do que pelo espanto, a admiração ou uma qualquer curiosidade pueril e ociosa, a atitude filosófica tem na sua raiz a consciência da dualidade eu-mundo, é induzida pela "verificação de que o mundo é algo que se nos contrapõe, que não é nós próprios, e é, portanto, um problema". ${ }^{31}$ Se a atitude filosófica desponta da simples consciência de si no seu contrapor-se ao mundo e está, por essa razão, ao alcance da consciência vulgar, já o filosofar é o momento de elevação dessa contraposição à categoria de problema, o qual se distingue do puro "mistério" justamente na medida em que ele é um "não-saber" que não permanece fechado, mas se passa num "saber de um não-saber" e se constitui, assim, como via para um "saber mais". Nesta medida, todo e qualquer problema, se corretamente formulado, "pressupõe a sua solução como possível", pois "de outra forma não teria sentido como problema e seria um mistério". ${ }^{32}$

É precisamente esse saber de um não-saber, tomado na sua máxima radicalidade, que faz emergir a questão gnosiológica como primeira tarefa da filo-

${ }^{29}$ Eduardo Soveral, "Sobre a essência do conhecimento. Comentário às posições de Miranda Barbosa". In: Pensamento Luso-Brasileiro. Lisboa: Instituto Superior de Novas Profissões, 1996, p. 99.

${ }^{30}$ Ibid., p. 101.

${ }^{31}$ Eduardo Soveral, O Método Fenomenológico. Estudo para a Determinação do seu Valor Filosófico, 1. Valor do Método para a Filosofia, ed. cit., p. 50.

${ }^{32}$ Ibid., p. 53. 
sofia. Ela implica, pela sua própria dinâmica, uma valorização do elemento da subjetividade - o problema é meu e para mim, como escreve Soveral e deve desenvolver-se metodicamente "por uma análise da estrutura cognitiva do sujeito", nomeadamente pela análise do pensar e do experimentar, enquanto raízes ou faculdades pelas quais todo o conhecimento se efetiva. ${ }^{33}$ É precisamente neste ponto que se verifica o encontro entre a reflexão de Soveral e o legado de Descartes e de Husserl. De fato, "uma prévia reflexão sobre o conhecimento a elaborar é cautela a que a fecunda mas incómoda herança cartesiana nos obriga". ${ }^{34}$ Ela impõe "a gnosiologia como a primeira e fundamental disciplina filosófica, dela ficando a depender a ontologia, a axiologia e a ética"; ela permite também desenvolver por vez primeira, de um modo metodicamente consequente, "o ideal de uma auto fundamentação do conhecimento crítico e, portanto, a exigência de um mínimo de pressupostos, ou seja, daquilo que, na "expressão feliz de Miranda Barbosa", veio a designar-se como o "mínimo filosófico"; ela abre, finalmente, "um plano gnósico sui generis - o plano transcendental - onde as análises imanentes do conhecimento se articulam antes mesmo de qualquer decisão doutrinária sobre o estatuto ontológico do fenómeno e da objetividade conhecida". ${ }^{35}$

Adentro desta perspetiva, a posição de Eduardo Soveral é firme e claramente expressa: perante as tarefas próprias da gnosiologia como disciplina filosófica inicial apontada à exploração preparatória do Problema Essencial do Conhecimento, "foi Husserl o autor que mais longe levou as investigações gnosiológicas orientadas neste sentido". ${ }^{36}$ Efetivamente, na senda de Miranda Barbosa e aprofundando o sentido das suas posições, observa Eduardo Soveral que a formulação cartesiana do cogito como o "mínimo filosófico" enferma de deficiências várias: "como Miranda Barbosa claramente advertiu, não pode ser atribuída ao cogito qualquer conotação existencial: nem a existência própria, como supôs Descartes, nem a existência dos próprios pensamentos, como inicialmente o filósofo português admitiu". ${ }^{37}$ Acresce ainda que esta suposta "intuição ou evidência racional" do cogito, ergo sum - a qual, na verdade, "não é nem uma coisa nem outra" 38 - conduziu Descartes a estatuir que "o cogito surge como uma existência que se auto fundamenta", como, portanto, uma verdade particular ainda antes da determinação essencial da ver-

${ }^{33}$ Ibid., p. 164.

${ }^{34}$ Eduardo Soveral, Imaginação e Finitude e Outros Ensaios. Lisboa: Imprensa Nacional-Casa da Moeda, 1999, p. 87.

${ }^{35}$ Ibid., pp. 58-59.

${ }^{36}$ Ibid., p. 84.

${ }^{37}$ Eduardo Soveral, Pensamento Luso-Brasileiro. Estudos e Ensaios, ed. cit., p. 105.

${ }^{38}$ Eduardo Soveral, Imaginação e Finitude e Outros Ensaios, ed. cit., p. 7. 
dade, "em vez de se revelar simplesmente como sujeito do conhecimento, fonte da evidência e condição da formulação e da solução do problema essencial do conhecimento". ${ }^{39}$

Contrariamente às deficiências internas da posição cartesiana, é, como ficou dito, em Edmund Husserl que Eduardo Soveral encontra a via para o mais claro e consequente equacionamento do Problema Essencial do Conhecimento. Essa via não é a transposição cartesiana da atitude filosófica para a esfera do juízo e da evidência intelectual - a qual se move no plano do puro pensar e toca o ser enquanto simples possível -, mas a da experiência na sua imediatez e radicalidade. ${ }^{40}$ A remissão para a subjetividade tem assim, em Husserl, o sentido da abertura e da instalação no plano transcendental (com a recondução do ego real e fáctico ao eidos-ego) e não a conotação existencial que, segundo Soveral, erroneamente conduzira Descartes a perder de vista o Problema Essencial do Conhecimento no próprio momento em que o engendrava. ${ }^{41}$ De acordo com caracterizações dos conceitos nucleares da fenomenologia que só esta apropriação criativa, por parte de Soveral, poderá legitimar, reduzir significará, assim, "simplificar, transpondo para um único plano", plano esse que se determina pelo movimento de transposição "da experiência espontânea do mundo ao plano da experiência interna do sujeito". ${ }^{42}$ Por via desta transposição, abre-se o domínio transcendental, o qual não tem que ver com qualquer esfera de aprioridade no sentido de $\mathrm{Kant},{ }^{43}$ mas com o domínio da experiência pura onde o Problema Essencial do Conhecimento pode ser levado à mais completa aclaração preliminar, preparatória de uma solução definitiva. Na verdade, para Soveral, "a estrutura gnosiológica da experiência interna - depois de liberta de todas as servidões que a prendem ao mundo, e depois de se ter revelado na sua configuração pura como vivência, isto é, como conteúdo unitário e organizado de experiência atual $[. .$.$] - surge-nos$ como sendo transcendental, isto é, como essencialmente indecisa quanto ao valor da experiência externa". ${ }^{44}$ Não é necessário sublinhar o quanto estas formulações se afastam do sentido autêntico dos conceitos husserlianos e da exata positio quaestionis de Husserl. No contexto de uma apropriação criativa, elas conduzem, porém, à plena inteligência do que é, na esteira de Miranda de Barbosa, o sentido e teor radical do Problema Essencial do Conhecimento.

\footnotetext{
${ }^{39}$ Eduardo Soveral, O Método Fenomenológico. Estudo para a Determinação do seu Valor Filosófico, 1. Valor do Método para a Filosofia, ed. cit., p. 116.

${ }^{40}$ Ibid., pp. 117 e ss.

${ }^{41}$ Ibid., p. 112.

42 Ibid., pp. 127 e 131.

${ }^{43}$ Ibid., pp. 132 e ss.

${ }^{44}$ Ibid., p. 132.
} 
Formulando-se literalmente como a questão de saber se o objeto intencional do conhecimento é imanente ou transcendente ao sujeito que o pensa, entendendo-se deste o início imanência como "pertença à esfera da subjetividade [...] ou à esfera que o sujeito pode direta e reflexamente reconhecer como sua", ${ }^{45}$ essa questão - que, em Husserl, se dissolve na distinção entre imanência real (do ato) e intencional (do noema) e na doutrina da constituição da transcendência objetual - conduz a estoutra interrogação, que se revela, agora, ser o sentido mais profundo do Problema Essencial do Conhecimento "haverá o transcendente, considerado como o absolutamente outro?" 46

$\mathrm{O}$ ensinamento mais basilar da analítica da consciência intencional tal como a praticou Husserl é, para Soveral, que a abertura ao objeto só como transfinita e inexaurível pode ser considerada. Esse é o dado mais importante da estrutura de horizonte. Segundo Eduardo Soveral, "a consciência reflete ou espelha sempre algo que não é ela própria; possui inevitavelmente um conteúdo heterónomo". Mas essa intencionalidade, enquanto abertura a algo como objeto, "é transfinita, isto é, por mais absorvente e pleno que seja o conteúdo da consciência, há sempre um horizonte mais vasto a rodeá-lo, para onde se projeta uma capacidade de aderência ou recetividade ao ser que não foi satisfeita" ${ }^{47} \mathrm{~A}$ este dinamismo essencial da consciência corresponde uma estrutura peculiar do "fenómeno puro", tal como ele se dá no plano transcendental. De feito, "o fenómeno puro", ou a objetividade como intencionalmente correlativa de uma noese, "é em si mesmo, enquanto aparição gratuita, na sua concreta, imediata e significativa objetividade, [algo que] anuncia um ser que se oculta enquanto se revela, ou seja, que constitutivamente se apresenta como transcendente". ${ }^{48}$

Deste dinamismo da consciência e desta abertura à transcendência do "fenómeno puro" tirará Eduardo Soveral amplos ensinamentos, que passam, nomeadamente, pelo primado do sujeito e abertura à relação ética firmada na liberdade, ou ainda pela impossibilidade de outrem ser reduzido, no plano intersubjetivo, à categoria de "fenómeno puro" na imanência. ${ }^{49}$ Mas o essencial da sua posição no que a uma confrontação com Husserl diz respeito é a circunstância de, neste contexto, firmando-se neste reenvio do próprio fenómeno para algo que nele se revela mas ao mesmo tempo se oculta como um para-lá,

\footnotetext{
${ }^{45}$ Ibid., p. 57.

${ }^{46}$ Ibid., p. 169.

${ }^{47}$ Eduardo Soveral, Imaginação e Finitude e Outros Ensaios, ed. cit., pp. 94-95.

${ }^{48}$ Eduardo Soveral, Fenomenologia e Metafisica. Porto: Centro Leonardo Coimbra da FLUP, 1997, pp. 46-47 (sublinhados nossos).

${ }^{49}$ Veja-se Eduardo Soveral, Ensaios sobre Ética. Lisboa: Imprensa Nacional-Casa da Moeda, 1993, por exemplo, pp. 18-19.
} 
se tornar, agora, a decisão pelo Idealismo, ao nível dos supostos gnosiológicos, sinónimo de um ceticismo e solipsismo insustentáveis, na medida em que ele cortaria cerce e só poderia considerar ilusório este reenvio para o Real contido na estrutura interna do "fenómeno puro": "o idealismo ou, talvez melhor designado, o subjetivismo, identifica-se, pois, com o solipsismo de um sujeito finito, o que obriga a concluir pelo mais radical e inapelável dos ceticismos". ${ }^{50}$ Resulta, assim, a conexão essencial, para Soveral, entre finitude do cogito e transcendência, num primado incontestável do eu, sem que, contudo, a egologia, caldeada nesta relação primitiva com o transcendente, se possa alguma vez volver "egolatria". 51

Fiel às suas teses diretoras, Eduardo Soveral constantemente afirma que a fenomenologia não é a sede para a solução do Problema Essencial do Conhecimento. Ela torna possível que, "aprofundando as exigências críticas do conhecimento", se progrida até o ponto em que "se considere fundada uma conclusão quanto ao estatuto ôntico do cogito e dos fenómenos". ${ }^{52} \mathrm{E}$ o teor dessa conclusão é agora por vez primeira inteiramente visível: o dinamismo da consciência implica um primado do cogito, mas esse mesmo dinamismo, enquanto abertura inexaurível ao ser a partir da estrutura de revelação/ ocultação do fenómeno puro, revela a finitude do eu e torna compreensível a posição de um Real absolutamente outro relativamente à consciência ou de uma transcendência "verdadeira", irredutível à esfera própria da subjetividade. "Excluída liminarmente a solução idealista como desejável, pois ela obrigaria a aceitar o mais radical dos ceticismos [...], deverá ser na busca da solução realista que haveremos de nos empenhar".

Esta solução para o Problema Essencial do Conhecimento, preparada numa fenomenologia assente na experiência, conduz "o método filosófico a significativas mudanças". Doravante, ele "não visará mais fundamentar o conhecimento científico, nem proceder a investigações transcendentais, mas passará a ter como objetivo o conhecimento das entidades ônticas que estão para além desse conhecimento e dessas investigações, devendo adequar-se, consequentemente, a esse seu novo propósito". ${ }^{53}$ Tais são os problemas da Liberdade e do ato ético, do Absoluto "hiper-pessoa" e "ser-em-si-para-si", do Amor excedente e, derradeiramente, da "douta ignorância" como correlato da relação com um Deus absconditus. ${ }^{54}$

\footnotetext{
${ }^{50}$ Eduardo Soveral, Fenomenologia e Metafisica, ed. cit., p. 33.

${ }^{51}$ Ibid., pp. 73 e ss.

52 Eduardo Soveral, Imaginação e Finitude e Outros Ensaios, ed. cit., p. 85.

${ }^{53}$ Idem, pp. 85-86.

${ }^{54}$ Veja-se, por exemplo, Soveral - Ensaios sobre Ética. Lisboa: INCM, 1993, pp. 79 e sgs., pp. 138 e sgs.
} 
Eis, em traços largos, o caminho de Eduardo Abranches Soveral pela e para lá da fenomenologia, bem como o modo como dela se apropria para as suas questões e preocupações teóricas mais próprias.

\begin{abstract}
In this paper, I present the main traits of the phenomenological thinking of Abranches de Soveral. I start with the work of his master Miranda Barbosa, explaining the criticisms he address to the Husserlian phenomenology. I show how Soveral's approach to phenomenology is framed by the conceptions of Barbosa and the problems that, for him, phenomenology cannot answer in an accurate way. In this context, I present the fundamental tenets of Soveral's rejoinder to his master, showing how phenomenology can be rearranged in order to formulate and to answer "the fundamental problem of knowledge".
\end{abstract}

